\title{
Fracture patterns in thin films and multilayers
}

\author{
Alex A. Volinsky \\ University of South Florida, Department of Mechanical Engineering, Tampa FL 33620 USA \\ Volinsky@eng.usf.edu \\ Dirk C. Meyer, Tilmann Leisegang, Peter Paufler \\ Institut für Strukturphysik, Fachrichtung Physik der Technischen Universität, D-01062 Dresden, \\ Germany
}

\begin{abstract}
While there are many stress relief mechanisms observed in thin films, excessive residual and externally applied stresses cause film fracture. In the case of tensile stress a network of through-thickness cracks forms in the film. In the case of compressive stress thin film buckling is observed in the form of blisters. Thin film delamination is an inseparable phenomenon of buckling. The buckling delamination blisters can be either circular, straight, or form periodic buckling patterns commonly known as telephone cord delamination morphology.

While excessive biaxial residual stress is the key for causing thin film fracture, either in tension, or compression, it is the influence of the external stress that can control the final fracture pattern. In this paper we consider phone cord buckling delamination observed in compressed W/Si and TiWN/GaAs thin film systems, as well as spiral and sinusoidal though-thickness cracks observed in $\mathrm{Mo} / \mathrm{Si}$ multilayers under 3-point high-temperature bending in tension.
\end{abstract}

\section{INTRODUCTION}

Thin films can support high levels of residual stress (up to several GPa), which are typically higher in compression compared to tension. Regardless of the residual stress sign, it causes substrate bending, and the resulting curvature can be used to calculate stress level in a thin film using Stoney's equation [1]. At higher levels of residual stress, or when in addition, external stress is applied, thin film fracture can occur. In case of residual tensile stress throughthickness cracking, film delamination, or even substrate cracking is observed [2]. Thin films buckle, delaminate and spall from the substrate when in compression. In a general, simplified form the strain energy release rate, $G$, in a stressed film, regardless of the stress sign is:

$$
G=Z \frac{\sigma_{f}^{2} h}{E_{f}}
$$

where $\sigma_{f}$ is the stress in the film, $h$ is the film thickness, $E_{f}$ is the modulus of elasticity, and $\mathrm{Z}$ is a dimensionless cracking parameter. More accurately, the energy release rate averaged over the front of advancing isolated crack is:

$$
G=g(\alpha, \beta) \frac{\pi\left(1-v^{2}\right) \sigma_{f}^{2} h}{2 E_{f}}
$$

where $g(\alpha, \beta)$ is a function of the Dundurs parameters $\alpha$ and $\beta$, and can be found in [3-4]. Film fracture or delamination is observed when the strain energy release rate exceeds the film $\left(G_{f}\right)$ or the interfacial $\left(\Gamma_{I}\right)$ toughness, respectively $\left(G>G_{f}\right.$, or $\left.G>\Gamma_{I}\right)$. One can avoid these types of failures 
by either reducing the film thickness, or the stress. Practically, the film thickness is easier to control. For a given stress level, there is a certain critical film thickness, at which failures are observed. This paper describes repeatable periodic fracture patterns observed in thin films and multilayers with tensile and compressive residual stresses.

\section{FRACTURE PATTERNS IN TENSION}

Though-thickness crack networks are known to form in drying media and thin films with residual tensile stress, and have been observed in several systems, including drying mud, spincoated hybrid organic-inorganic coatings at high temperatures [5], drying coffee-water mixture [6], low-K dielectric thin films (Figure 1) [7], alumina/water slurry dries [8], and even in monolayers of microspheres [9]. Theoretical considerations can be found in [10-12]. While a fracture pattern, similar to one shown in Figure 1 is most common in residual tension, other, more peculiar fracture patterns have been observed. For example, spiral cracks were found inside the delaminated regions of drying precipitates of different compounds, including nickel phosphate, ferric hydroxide and others [13]. Originally spiral cracks have been observed in etched Pyrex glass under stress [14], and inspired Xia and Hutchinson to provide a theoretical explanation of the phenomena in terms of the crack interaction and the mode mixity effects [15]. Similar crack patterns have been observed in the Mo/Si multilayer system (Figure 2a), and were originally reported in [16]. Here, Mo/Si multilayers ( $2 \mathrm{~nm} \mathrm{Mo} \mathrm{and} 3 \mathrm{~nm} \mathrm{Si}$ for the $500 \mathrm{~nm}$ total thickness) were sputter deposited onto Si wafers. Sample strips 20x8 mm were cut out, and then tested in 3-point bending between ruby crystal supports at high temperatures up to $440{ }^{\circ} \mathrm{C}$ in vacuum, which caused multilayer film fracture. While the residual stress in the multilayer was not measured at elevated temperatures, the maximum bending stress is estimated to be on the order of $250 \mathrm{MPa}$.
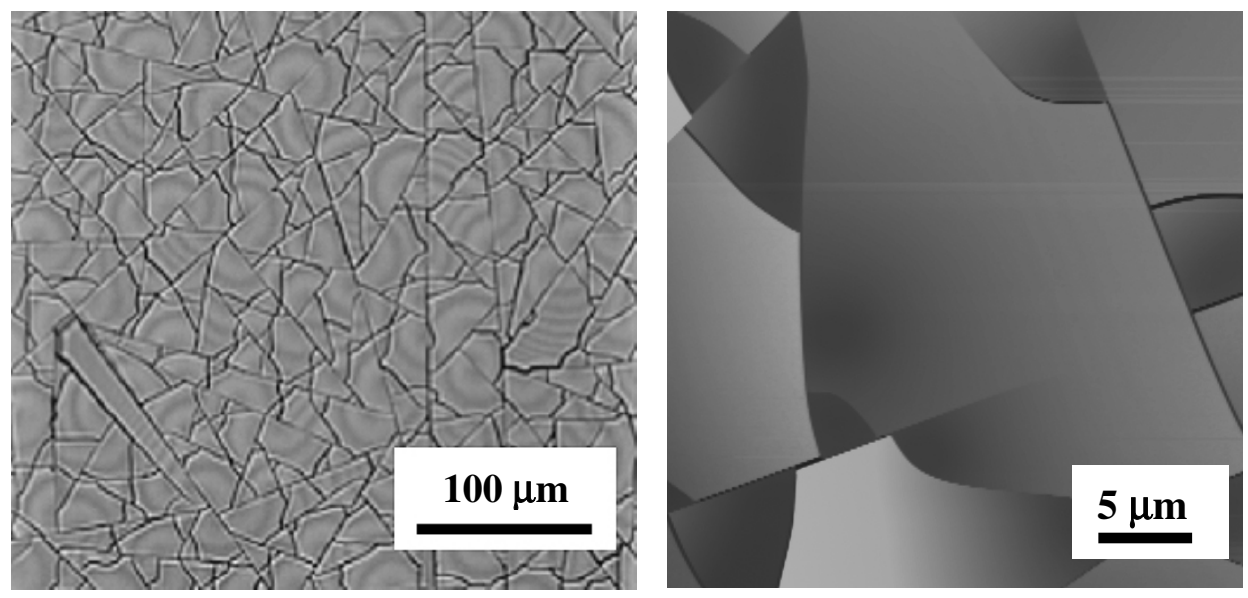

Figure 1. Optical and AFM images of though-thickness cracks in low-K dielectric thin film.

Sinusoidal cracks were also observed simultaneously with spiral cracks on the same sample (Figure 2b, Figure 3). Sinusoidal crack patterns have been reported in bulk glasses rapidly immersed into cold water [17], and the straight-to sinusoidal transition was found to depend on the immersion velocity and the temperature gradient. In our case there is an influence of external bending stress in addition to the temperature effects, and the fact that the cracks propagate in a multilayer system vs. bulk glass. While both spiral [13, 14] and sinusoidal [17] 
cracks have been observed in bulk systems under certain conditions, according to the authors' knowledge, this is the first report of spiral and sinusoidal cracks observed in thin films. We stress again that both spiral and sinusoidal cracks occur in one sample (Figure 3).

Unlike the 4-point bending configuration, the externally applied stress is not evenly distributed along the sample length for the 3-point bending: it reaches a maximum in the middle of the sample, and is negligible outside of the outer supports. The fact that cracks appear even outside the region of externally applied stress in a 3-point bending configuration suggests that the stress from 3-point bending is not solely responsible for the phenomenon. While the external bending stress combined with high temperature may induce fracture, it is probably not sufficient to produce repeatable fracture patterns schematically presented in Figure 3. It is most likely a combination of biaxial residual stress, temperature with externally applied tensile stress, and possibly asymmetric film debonding that cause these repeatable periodic fracture patterns. The exact root cause would be subject of a further detailed study, as both types of multilayer fractures are in fact accompanied by some film debonding from the substrate.
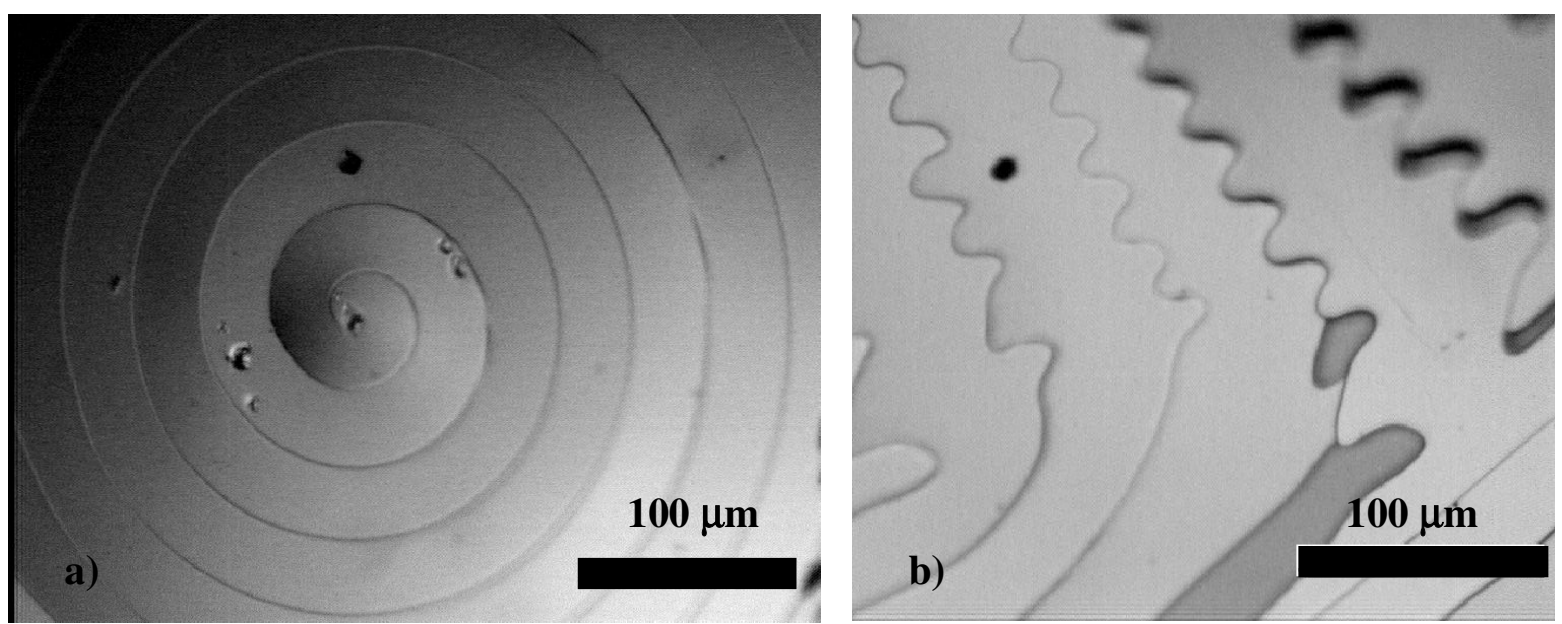

Figure 2. Optical images of a) spiral and b) sinusoidal cracks in the Mo/Si multilayer.

(c) force (out of plane)

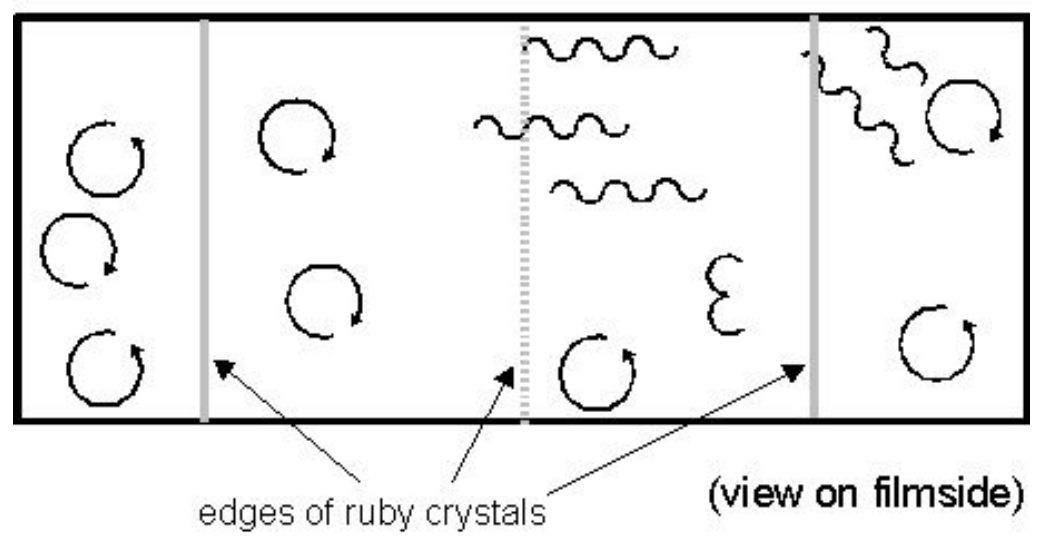

Figure 3. Schematics of cracks layout in the Mo/Si multilayer sample. 


\section{FRACTURE PATTERNS IN COMPRESSION}

Films under compressive stress typically buckle, delaminate from the substrate, and sometimes fracture by forming through-thickness cracks when buckling stress exceeds film fracture stress [18]. A most common fracture pattern in case of residual compressive stress relief in thin films is the "telephone cord" delamination. Sinusoidal buckled features are called "telephone cords", since they remind a twisted phone cord in the optical microscope (Figure 4a, bottom feature), and have been observed in several thin film systems [19-25]. The residual stress in the thin film has to exceed the film buckling stress by a factor of four for the telephone cords to exist [24]. It has been shown that the telephone cord may start out as a straight blister, and then convert into a sinusoidal shape by means of "secondary" buckling [25]. If the residual stress is less than 4 times the buckling stress, straight blisters become possible under biaxial residual compressive stress, but then the level of residual stress may not be high enough to initiate delamination, that is why residual stress-induced straight blisters are rarely observed in thin films. This situation changes though when the stress is applied externally, for example in 3 or 4point bending of the substrate. A simple experiment with the compact disc (CD) 3-point bending has been described in [25] to support the point that the case of external uniaxial compression differs from the case of biaxial compressive residual stress. While the stress component perpendicular to the blister propagation direction has been relieved by film buckling, the stress along the blister propagation direction is partially relieved by "secondary" film buckling, thus telephone cord formation. The actual transition process from initially straight to telephone cord blister can be seen in a live movie published online [26]. While the sides of the straight blister are primarily under mode II conditions, the delamination can still propagate sideways and branch in case of relatively high residual stress in the film.

While the residual stress in the film is biaxial, i.e $\sigma_{x x}=\sigma_{y y}$, there is always an effect of external stress due to substrate bending or warpage, which along with the in-plane residual stress gradients may control the overall directionality of the telephone cord blisters. This explains why telephone cords normally run parallel to each other in a certain direction.
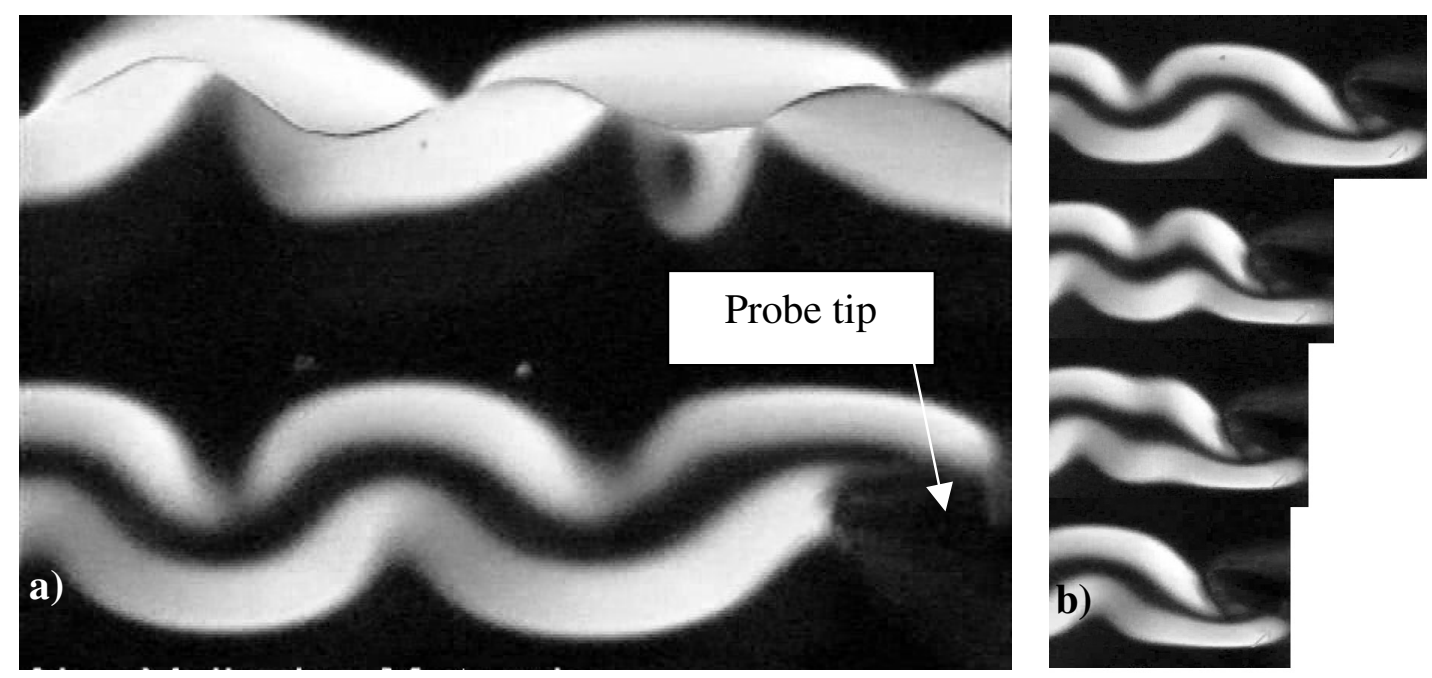

Figure 4. a) Optical micrograph of the telephone cord delaminations in the W/Al/Cu system;

b) "Secondary" buckling manipulation with a probe. 
The idea of "secondary" buckling was also supported by an experiment, in which a microprobe was used to manipulate the already existing telephone cord shown on the bottom of Figure $4 \mathrm{a}$. Barely touching the top of the telephone cord blister, microprobe was moved in the direction parallel to the blister, which has caused the "secondary" buckle motion along the blister direction, as shown in Figure 4b. The process is completely reversible, i.e. the telephone blister does not change the shape when the probe is moved all the way back to the right. This is similar to manipulation a buckled piece of paper bound by two parallel plates. Figure $4 \mathrm{~b}$ also shows that the telephone cord contour as it appears in the optical microscope does not correspond to the film delamination contour, as discussed in [25]. Film fractured along the maximum buckling amplitude line on the top of Figure 4a image due to excessive probe manipulations.

Patterns, similar to telephone cords have been also observed in films bonded to compliant substrates (Ex. metal film on a polymer substrate). Here, thin film deformation can be accommodated by the substrate deformation without film delamination. Similar patterns are also observed in thermal damage of thin films. Figure 5 shows an electron beam-induced damage in a $3 \mu \mathrm{m}$ thick $\mathrm{SiO}_{2}$ layer on top of $\mathrm{Si}$. This occurred in an Auger system as a result of performing a beam line scan. Here, the similarity with the telephone cord delamination geometry is clear. Theoretical treatment of thin film warping in top of compliant substrates can be found in [27].

Figure 5. AFM image of an electron beam-induced damage in $\mathrm{SiO}_{2}$ on top of a $\mathrm{Si} 3$ wafer and a
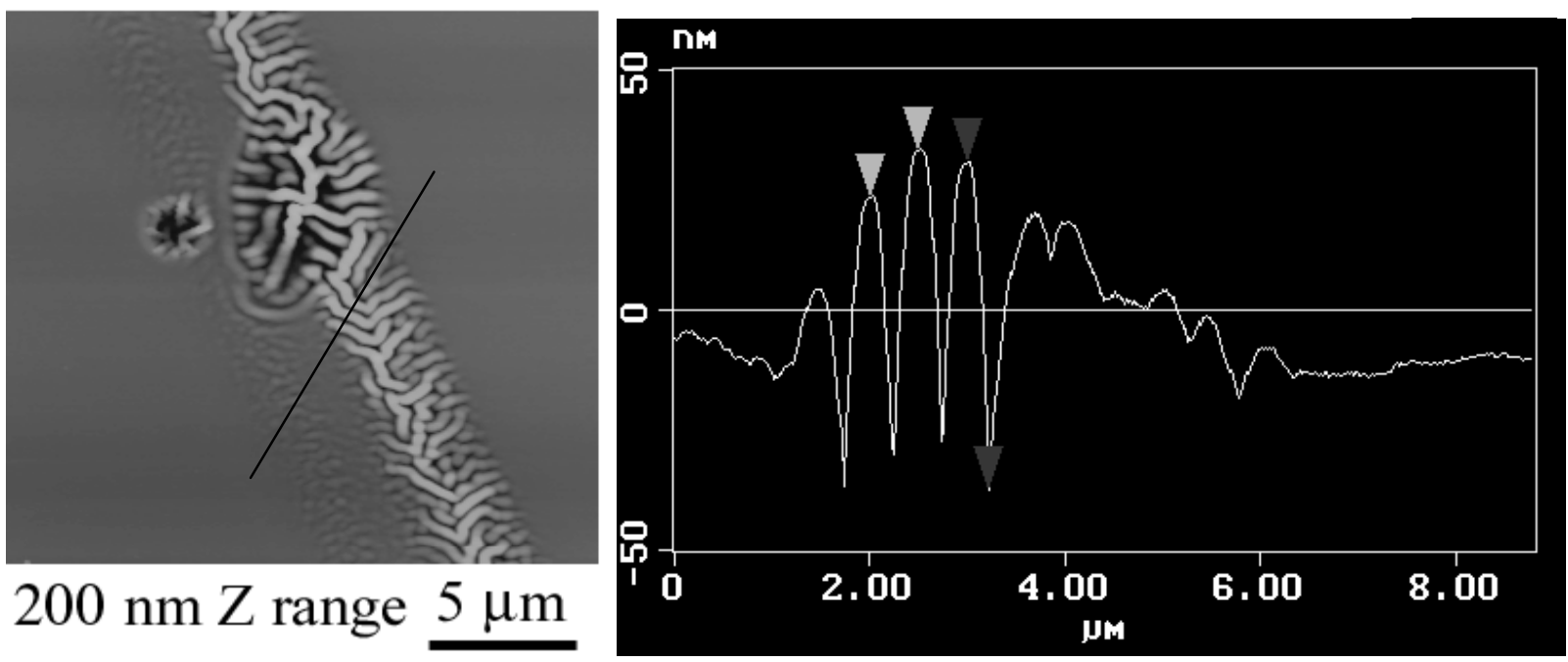

corresponding cross-section.

\section{CONCLUSIONS}

We have considered repeatable periodic fracture patterns observed in thin film and multilayers in tension and compression. Spiral and sinusoidal through-thickness cracks have been observed in Mo/Si multilayers under 3-point bending at high temperature in vacuum. Telephone cord delamination appears to be a common morphology in films under biaxial compressive stresses. This kind of pattern is due to the fact that the residual stress in thin films is biaxial. Straight buckling delaminations are observed under the influence of external uniaxial stress. There is a similarity in the patterns with compressed films on compliant substrates and thermal damage in thin films. Further discussion is a subject of a more detailed paper [28]. 


\section{ACKNOWLEDGEMENTS}

The authors would like to thank Professors T.G. Eason, A.K. Kaw, G.H. Besterfield, J.W. Hutchinson, and W.W. Gerberich for valuable discussions. Thanks to W.M. Clift and N.R. Moody from Sandia National Lab, Livermore for Auger analysis. This research was partially supported by Sandia National Lab, Livermore and Motorola.

\section{REFERENCES}

1. G.G. Stoney, Proc.Roy.Soc.Lond. A82, 72 (1909)

2. M.D. Thouless, J. Vac. Sci. Technol. A 9(4), 2510-2515 (1991)

3. J.W. Hutchinson; Z. Suo, Advances in Applied Mechanics 29, 63-191 (1992)

4. J.L. Beuth, Int. J. Solids Struct. 29, 1657 (1992)

5. J. Malzbender, G. de With, Thin Solid films 359, 210-214 (2000)

6. A. Groisman, E. Kaplan, Europhys. Lett. 25(6), 415-420 (1994)

7. A.A. Volinsky and W.W. Gerberich, Microelectronic Engineering 69/2-4, 519-527 (2003)

8. K.A. Shorlin, J. R. de Bruyn, Phys. Rev. E 61(6), 6950 (2000)

9. A.T. Skjeltorp, P. Meakin, Lett. to Nature 335, 424 (1988)

10. M.D. Thouless, J. Am. Ceram. Soc. 73, 2144 (1990)

11. T. Bai, D.D. Pollard, H. Gao, Lett. to Nature 403, 753 (2000)

12. R. Huang, J.H Prevost, Z.Y. Huang, Z. Suo, Eng. Fract. Mech. 70, 2513 (2003)

13. Z. Neda, K.-t. Leung, L. Jozsa, M. Ravasz, Phys Rev. Lett. 88(9), 95502 (2002)

14. A. Argon, Proc. Roy. Soc. A250, 472-481 (1959)

15. Z.C. Xia, J.W. Hutchinson, J. Mech. Phys. Solids 48, 1107-1131 (2000)

16. D.C. Meyer, T. Leisegang, A.A. Levin, P. Paufler, A.A. Volinsky, Appl. Phys. A 78, 303305 (2004)

17. A. Yuse, M. Sano, Nature 362, 329 (1993)

18. B. Cotterell, Z. Chen, Int. J. of Fractrure, 104, 169 (2000)

19. A.A. Volinsky, N.R. Moody, W.W. Gerberich, Acta Mater. 50(3), 441 (2002)

20. A.A. Volinsky, N.R. Moody, M.L. Kottke, W.W. Gerberich, Philosophical Magazine A, 82 (2002)

21. N. Matuda, S. Baba, A. Kinbara, Thin Solid Films 81, 301 (1981)

22. G. Gille, B. Rau, Thin Solid films 120, 109 (1984)

23. J. Seth, R. Raghunath, S.V. Babu, J. Vac. Sci. Technol. A 10(2) (1992)

24. M.-W. Moon, H.M. Jensen, J.W. Hutchinson, K.H. Oh, A.G. Evans, J. Mech. Phys Solids, 50(11), 2355 (2002)

25. A.A. Volinsky, Mat. Res. Soc. Symp. Proc. 749, W10.7 (2003)

26. http://www.eng.usf.edu/ volinsky

27. J. Liang, R. Huang, H. Yin, J.C. Sturm, K.D. Hobart, Z. Suo, Acta Mater. 50, 2933 (2002)

28. A.A. Volinsky, et. al., to be published 